\title{
Pre-Service Teachers' Perception Toward Environmental Knowledge, Attitudes and Behaviours
}

\author{
MOHAMAD TERMIZI BORHAN ${ }^{1}$ \\ ZURIDA ISMAIL ${ }^{2}$ \\ School of Education \\ Universiti Sains Malaysia \\ mohamad_termizi.pm08@student.usm.my ${ }^{1}$ \\ zurida@usm.my ${ }^{2}$
}

\begin{abstract}
Purpose - The study investigated the environmental knowledge, attitudes and behaviours exhibited by the pre-service teachers and determined if there was any significant relationship between environmental knowledge, attitudes and behaviours.
\end{abstract}

Method - This descriptive study adopted a quantitative approach using questionnaires to obtain information on environmental knowledge (53 items with true/false responses), environmental attitudes (11 items with a 4-point Likert scale) and environmental behaviours (11 items with a 4-point Likert scale) of $1733^{\text {rd }}$-year students enrolled in the Chemistry Teaching Methods course. Data were analysed using both descriptive statistics (frequency, percentage, mean and standard deviation) and inferential statistics (correlation coefficient).

Findings - The low total mean score on the environmental knowledge component indicated the respondents' lack of knowledge on environmental issues especially in climate change, However, the respondents exhibited high positive environmental attitudes based on their responses to the relevant attitude items especially on items that related to adopting significant actions. Most of the items in the environmental behaviours component yielded considerably high mean scores which indicated a strong willingness on the part of the pre-service teachers to take pro-environmental behaviours. The findings also showed that there was no significant relationship between knowledge, attitudes and behaviours. 
Significance - The study highlighted the need to review the curriculum on environmental education in teacher-training courses so as to provide pre-service teachers with knowledge on environmental issues, as well as to develop favourable attitudes and behaviours of students regarding environmental issues.

Keywords: Pre-service teachers, environmental knowledge, environmental attitudes, environmental behaviours.

\section{INTRODUCTION}

Climate change, one of the world-wide dimensions of environmental problems has raised national and international concern. The American Geophysical Union (2007) in their recent position statement has documented that the Earth's climate is clearly warming. According to IPCC $(2007$, p. 4) global greenhouse gas emissions due to human activities have grown since pre-industrial times, with an increase of $70 \%$ between 1970 and 2004. In the recent UN General Assembly, President Obama said that the threat from climate change is serious, urgent and growing (Huffington Post, 2009). As the general public has become increasingly aware of the environmental problems facing the world today, the so-called 'green issues' have become important political matters as well as discussion topics in mainstream conferences. The problem is caused by human beings alone, and the most effective solution to the environmental problems would be to enlighten society on the subject of environment along with legal arrangements. As John F. Kennedy once observed "Our problems are man-made, therefore they may be solved by man".

The cause and effect relationship between human activity and the environment must often be learned through educational processes. Through formal education, ways of thinking and behaviour of the students are cultivated apart from the acquisition of the knowledge and dexterities, attitudes, perceptions (Skanavis, Petreniti \& Giannopoulou, 2004). Empirical evidence also suggests that pro-environmental behaviour is predicted by knowledge and education (Barr, 2007; Weaver, 2002). Environmental Education (EE) is considered as an essential component of education for future citizens in order for them to be able to confront and deal with the upcoming environmental issues. EE is one of the tools that help to achieve sustainable development. EE is also an instrument to enable 
the participation and learning of various age-groups based on twoway communication, both formal and non-formal. Through the process of EE, individuals obtain an understanding of the concepts of and knowledge about the environment. They also acquire experience, values, skills and the knowledge necessary to form judgments to participate in decision-making and to take appropriate action in addressing environmental issues and problems.

EE was first defined in the Tbilisi Declaration which affirmed international commitment to international environmental education. This commitment to create awareness about the environment in the general population and changes in the human behaviour must be made in order for individuals and social groups to be actively involved, at all levels, in working towards the resolution of environmental problems (UNESCO-UNEP, 1978). EE was re-oriented and renewed to the direction of sustainable development in 1992 at the Earth Summit in Rio de Janeiro and is manifested in Chapter 36 of Agenda 21. Chapter 36 of Agenda 21 stresses on the following: Education, including formal education, public awareness and training, should be recognized as a process by which human beings and societies can reach their fullest potential. Education is critical for achieving environmental and ethical awareness, values and attitudes, skills and behaviour consistent with sustainable development and for effective public participation in decision-making. The publication of the Agenda 21 Report strengthens the effort and is regarded as a blue-print for countries to pursue sustainable development. It is a plan to achieve a sustainable society in this environmentally and economically inequitable world. With rapid population increase and economic growth in many countries, the environment is becoming more vulnerable and natural resources are depleted faster to meet basic needs.

Malaysia, as with most countries in the region, has reacted to integrate EE in the curriculum. The Education Planning Committee of the Ministry of Education had made the decision to integrate and infuse EE throughout the New Primary School Curriculum (NPSC) and the Integrated Curriculum for Secondary Schools (ICSS) in 1991 (Thiagarajan \& Norshidawati, 2005). In line with the recommendations of Agenda 21 also, Malaysia's National Policy has outlined Green Strategies which emphasize Education and Awareness (Ministry of Science, Technology and the Environment (MOSTE), 2002). EE in Malaysia is geared towards addressing environmental challenges such as littering, water pollution, air 
pollution and the degradation of biodiversity (Susan, Tagi \& Periasamy, 2005). The school curriculum is focused educating the society to be more sensitive and concerned about environmental issues, to be knowledgeable, skilled and committed to act individually or collectively to address environmental issues. At the tertiary level, various environmental science and environment-related courses are offered at degree level. After years of research, several local universities have built up their expertise in the environment-related fields (Arba`at, Kamisah \& Pudin, 2009).

Against this background, teachers who have always been regarded as the agents for social changes, play a very important role to environmentally educate and encourage students' interest in environmental issues. The implementation of $\mathrm{EE}$ definitely depends initially on the attitudes or the receptivity of teachers to this innovation (Skanavis et al., 2004). Kaplowitz and Levine (2005) concluded from their research concerning the level of environmental knowledge of university students that increasing the level of environmental knowledge of tomorrow's teachers may be both possible and fruitful to help improve environmental education efforts. Nguyen (2001) reported, for example, the quality of EE in primary schools depends on teachers' awareness and attitudes. Prospective teachers therefore, have to be equipped with good environmental knowledge, attitudes and behaviour. As rapid advances are made in environmental science, it is essential for educators to have up-todate, relevant teaching material that present basic concepts in ways that could stimulate student interest. It is important that teachers not only support the goals of EE theoretically but to also feel a personal responsibility to implement EE in their classrooms (Volk, 1982).

Studies of trainee teachers' ideas about global environmental issues have suggested that teachers might be less than well prepared in this respect (Boyes, Chambers \& Stanistreet, 1995). A descriptive study by Lim (2005) in two schools in Selangor as well as Sharifah, Laily and Nurizan's (2005) study showed that students' and teachers understanding of environmental issues and recognition of environmental problems were only at the surface level. Teachers lacked a general understanding of the underlying causes of environmental problems (Aini, Fakhrul, Lily \& Jariah, 2003). Aini et al. (2003) also reported that the practices of environmental behaviour among teachers were not in concert with the level of environmental concerns and knowledge. Similarly, Tuncer, Sungur, Tekkaya, and Ertepinar (2007) found that the pre-service teachers in their study 
displayed more favourable attitudes and more awareness of the importance, meaning and integration of individual responsibilities with lifestyles, consumption patterns and environmental problems. However, the pre-service teachers were unclear about the solutions and the general attitude to solutions, to environmental problems cannot be evaluated as promising. Tuncer et al. (2007) suggested that the reasons for such an attitude can be explained by several means; the major one being a lack of environmental knowledge.

If teachers do not have sufficient knowledge, dexterity or the desire to implement EE in the programme, it is improbable that environmentally-literate students will graduate from school. In order for students to have sound knowledge and good values towards the environment, the knowledge-base of the teachers themselves is of great importance as good subject knowledge is essential for best teaching (Summers, 1994). Many support the notion that educators need to have deeper and wider knowledge than their students, for a number of reasons: i.e., to be able to "diagnose" the students' learning difficulties, to correspond flexibly to their needs and to answer unanticipated questions (Summers, Kruger \& Childs, 2001). Indeed many studies have investigated teachers' and prospective teachers' ideas (Groves \& Pugh, 2002; Khalid, 2003; Papadimitriou 2004; Summers, Kruger, Childs \& Mant, 2000); the results show that teachers also hold misconceptions and misunderstandings about climate change. Among the identified misconceptions are global warming is caused by increased penetration of solar radiation, that it is connected with holes in the ozone layer, that it would result in increased skin cancer, and that the use of unleaded petrol would reduce it. Across most groups examined, there appeared to be a general conflation of thinking about global warming and ozone layer depletion (Boon, 2010).

There is widespread opinion that teachers' conceptions of pedagogy play a crucial role in their effectiveness as primary mediators between the subject and the learner (Kyridis, Mavriki \& Tsakridou, 2005). Teachers need to know and accept content, evaluate student ideas and understanding, and provide learning experiences to align students' conceptions with scientific explanations. It is therefore, important that prospective teachers, who are in a position to influence their students, begin their teaching careers with a clear understanding of at least the basics of a topic as important as climate change. As Sharifah Norhaidah (2006) asserts, pre-service teachers need to be equipped with the knowledge 
of action strategies, to understand the intricacy of the problem involved and more importantly to be sensitized to the root causes of unsustainable future, as upon graduating, they are supposed to infuse environmental education or sustainability education into the Malaysian Secondary Curriculum. In order to deal with these growing issues, a survey was conducted to assess the pre-service teachers' environmental knowledge, attitudes and behaviours.

\section{METHODOLOGY}

The study involved 173 pre-service teachers enrolled in a Chemistry Teaching Methods course. The students were in their third year of the teacher-education programme. Data were collected through a survey using questionnaires. The survey was a non-experimental, descriptive research method. Surveys can be useful when a researcher wants to collect data on phenomena that cannot be directly observed (King \& He, 2005). The questionnaire was administered in English and consisted of three parts: environmental knowledge, attitudes, and pro-environmental behaviour. The time required to complete the survey was approximately 30 to 45 minutes.

\section{Environmental Knowledge}

Environmental knowledge refers to the knowledge and understanding of facts, concepts and generalizations related to environmental concerns (Chin Ivy et al., 1998). It is defined as the information that enables someone to study and reach conclusions about the physical, social and cultural conditions that affect the development of an organism. Environmental knowledge tested for causes (16 items), consequences (19 items) and cures/solutions (18 items) of climate change. Each of the sections contained items expressing scientifically-accepted statements and idiosyncratic statements, that is, ideas which oppose the scientific explanation, also known as misconception or alternative conception. The instrument was adapted from the questionnaire developed by Boyes, Chamber and Stanistreet (1993). The items used a True/False format and scoring for each item was done by allocating one point for each correct answer giving a possible range of 0 to 53 for the overall environmental knowledge score. The Cronbach coefficient alpha or internal consistency for the knowledge section was 0.789 . 


\section{Environmental Concern Scale (Environmental Attitudes)}

Environmental attitudes deal with the affective domain, evaluating whether the students agree or disagree, are favourable or unfavourable, with regard to aspects of the environment. It is defined as the predispositions that affect how someone perceives and interprets the physical, social, and cultural conditions that affect the development of an organism (De Chano, 2006). To measure attitudes towards the environment, the Environmental Concern Scale consisting of 11 items was used. The Environmental Concern Scale consists of two dimensions (Chan, 1996): personal sacrifice with five items (Q1, Q3, Q6, Q7, and Q11) and optimism/issue with six items (Q2, Q4, Q5, Q8, Q9, and Q10). Personal sacrifices refer to the willingness of the respondents to act to protect the environment although this action will require sacrifice of time and money. Optimism/Issue refers to the tendency of the respondents to believe that there are always solutions for environmental problems. For instance, they believe that contamination of rivers, oceans and air will soon return to normal by nature's purifying processes. The questionnaire was first developed by Weigel and Weigel (1978). The items used a fourpoint Likert-type scale ranging from Strongly Agree to Strongly Disagree. The Cronbach alpha or internal consistency for the attitude section was 0.630 .

\section{Pro-environmental Behaviour}

Environmental behaviour refers to the overt and observable actions taken by a student in response to the environment. Hence, programmes created to enhance environmental awareness should be designed to engage the target audience in not only increasing their environmental knowledge but their environmental skills, attitudes and behaviour as well (Grodzinska-Jurczak et al., 2003). Environmental behaviour was measured using 11 pro-environmental behaviour statements. Students were required to indicate their willingness to participate in pro-environmental behaviour. The statements were taken from two different sources: Chan (1996) and Volk and McBeth (1997). The items also utilized a four-point Likert-type scale $(1=$ strongly agree and $4=$ strongly disagree) which was used for the codification of the answers. The behaviours were selected on the basis that (1) the students would be familiar with them and that they were within their capabilities to participate, (2) the behaviours were clearly related to the environmental issues and (3) the behaviours were different 
in nature and situations (Chan, 1996). The internal consistency of the behavioural intention score, as measured by the Cronbach coefficient was found to be very high (0.831). This indicates that the pro-environmental behaviour was selected from a consistent set of behavioural indicators.

\section{RESULTS AND DISCUSSION}

The results of the study are discussed in four parts: students; environmental knowledge, attitudes, students' willingness to participate in pro-environmental behaviour and the degree of relationship between environmental knowledge, attitudes and behaviour. The analysis and discussion on environmental knowledge are divided into three aspects: causes, consequences and cures/ solutions.

\section{Table 1}

Mean and Standard Deviation of Climate Change Knowledge According to Component

\begin{tabular}{lrl}
\hline Component & Mean & SD \\
\hline Causes (16 items) & 8.10 & 1.29 \\
Consequences (19 items) & 12.64 & 1.854 \\
Cures/solutions (17 items) & 10.86 & 1.631 \\
Overall (52 items) & 31.59 & 3.638 \\
\hline
\end{tabular}

Descriptive statistics related to students' correct responses on climate change are presented in Table 1; calculated based on the component of climate change knowledge as well as for the overall questionnaire. The causes component shows that most of the students only managed to answer half of the components correctly. While for the consequences and the cures/solution components, students only demonstrated moderate ability to answer these components. The relatively low mean total knowledge score indicated that students did not acquire a satisfactory understanding of the environmental issues, specifically in climate change. The standard deviations were relatively small. These deviations, which ranged from 1.29 to 3.638 indicated that students' environmental knowledge was relatively consistent and uniform. 


\section{Causes of Climate Change}

The first component of the questionnaire was designed to examine the distribution of student's knowledge and misconceptions about factors that cause climate change. Table 2 shows the frequency count for each item which causes climate change. The causes of climate change dealt with factors or human activities that exacerbate climate change. Students are well informed about the causes of climate change if the statements had high percentages of correct responses. Generally, most of the students knew that increase in $\mathrm{CO}_{2}$ and CFC concentration in air composition, deforestation, artificial fertilizer gases, and the heating and cooling systems in the house are among the factors that could lead to climate change. However, only a small number of students $(25.8 \%)$ knew eating meat is one of the contributing causes. In a special report on health and energy in the latest version of the medical journal The Lancet, experts urged people to consume less steak and burger. It also reported that reducing global red meat consumption by $10 \%$ would cut the gases emitted by cows, sheep and goats that contribute to global warming.

Table 2

Percent of Correct Responses for Scientific and Idiosyncratic Statements of Causes of Climate Change

Items

$\%(\mathrm{~N}=182)$

\section{Scientific Statement}

- Increase $\mathrm{CO}_{2}$ volume in air composition

100.0

- Gas from artificial fertilizers

- Rainforest depletion

- Eating meats

- Too much CFC volume in air composition

- Rotting waste

- Use of heating \& cooling systems in house

- Too much ozone near the ground 27.5

- Sunrays cannot escape from the earth 77.5 
Idiosyncratic Statement:

- Rubbish dumped in rivers and streams

- Use of aerosol spray and refrigerators

- Acid in the rain

- Radioactive waste from nuclear power stations

- Holes in the ozone layer

- Space programme (punches holes in the atmosphere)

There are three most prevalent misconceptions regarding causes of climate change: using aerosol spray and refrigerators, space programmes that can punch holes in the atmosphere and holes in the ozone layer. They was confusion between global warming and ozone depletion, as the majority though that the "hole" in the ozone layer is one of the causes of global warming (Boyes et al., 1993; Groves and Pugh, 1999). In Papadimitriou's (2004) research, the explanation given by the students was that the ozone "hole" allows more sunlight to penetrate the atmosphere and heat the earth. The ozone hole only exposes the earth to higher UV radiation levels from the sun. Although also harmful to life, the ozone hole problem differs from that of global warming. Rye, Rubba, and Wiesenmayer (1997) found that 54\% of the students believed that ozone layer depletion was the predominant cause of global warming. In general, connecting ozone layer depletion with climate change seems to be the common misconception held by people of all ages.

Using aerosol cans has almost no effect on climate change. In the past, aerosol spray cans contained CFCs which contributed to the depletion of the ozone layer (not the same as global warming). However, the sale of aerosol cans containing CFCs has been banned in the United States and Canada since 1979. A notable misconception is related to the view that climate change is connected with the radioactive waste and a significant percentage of the students named acid rain as one of the causes of climate change. In the Kilinc, Stanisstreet and Boyes' (2008) study, radioactivity was held by more than half of the students to be a cause of global warming. The misconception concerning causes of climate change, probably has implication in affecting peoples` ideas about action taken to alleviate it. As Morgan, Fischhoff and Read (1994) have claimed, when causes are not well understood, it is clearly difficult 
to devise effective solutions to the problem and this may lead even concerned citizens to avoid undertaking the proper action.

\section{Consequences of Climate Change}

The second component of the questionnaire was designed to examine the distribution of student knowledge and the misconception about the effect of climate change. Table 3 shows the frequency counts for each item of the consequences of climate change. The consequences of climate change dealt with what might happen or had already happened if the climate change got bigger. According to the results, most of the students (more than $80 \%$ of the population) were well informed about the real consequences that might happen or had already happened with the occurrence of climate change. They were aware and knew that changes in the global weather pattern could lead to a hotter earth, the melting of ice will result in the sea water level rising, loss of habitat for polar bears and penguins, and flooding. However, only $2 \%$ knew that climate change will never cause skin cancer. Kilinc, Stanisstreet and Boyes (2008) found that the most common misconception, held by more than three quarters of the students was that global warming would result in an increase in the prevalence of skin cancer. Perhaps this misconception is based on a deeper confusion between climate change and ozone layer depletion. Most of them were aware that ozone layer depletion will increase the incidence of skin cancer, but may thought that climate change was linked to ozone layer depletion, either caused it, or was caused by it (Pekel \& Ozay, 2005).

\section{Cures/Solutions of Climate Change}

The third component of the questionnaire was designed to examine students' knowledge and misconceptions about how climate change might be ameliorated. Table 4 shows the frequency count for each item (both scientific and idiosyncratic statements) on cures/solutions of climate change. Cures/solutions of climate change discuss measures the students may adopt to mitigate the impact of climate change on the environment, economy, lifestyles and community. Most of the students correctly mentioned them and were able to identify steps or actions that can alleviate climate change such as plant more trees, recycle the trash, less use of cars as well as more frequent use of public transportations. The majority of the students 
also affirmed that saving electricity could lead to a reduction in climate change. This is good because this is one action that falls partly within the locus of control of the students themselves. Furthermore, the establishment of good habits during young years might well persist into lifetime practice (Kilinc, Stanisstreet \& Boyes, 2008). However, the advantages of nuclear power as one of the solutions for climate change were appreciated by only $16.5 \%$ of the students. This may be because nuclear power has a negative environmental image, possibly due to the accidents in nuclear power stations or they associated it with nuclear warfare.

\section{Table 3}

Percent of Correct Responses for Scientific and Idiosyncratic Statements of Consequences of Climate Change

(1)

Items $\%(\mathrm{~N}=182)$

Scientific Statement:

Change in global weather pattern

100.0

Ice of the both poles will melt

98.4

Flooding will occur more frequently

89.0

More deserts in the world

65.4

Earth becomes hotter

97.3

More pest and bug population

55.5

- Sea level rises and coastal erosion

96.7

Loss of habitat for polar bears and penguins

96.2

Mass extinction of many animal species

87.9

Certain types of disease will spread

96.2

Some regions may become prone to deadly storms

80.2

Affect global agriculture output

92.9

Idiosyncratic Statement:

- More earthquakes occur

- Fish and other aquatic life poisoned

- People will get food poisoning

- Skin cancer to human

- Unsafe to use tap water

- More people will die of heart attack

- War among countries 
Table 4

Percent of Correct Responses for Scientific and Idiosyncratic Statements of Cures/Solutions of Climate Change

Items

$\%(\mathrm{~N}=182)$

Scientific Statement:

- Save electricity

- Plant more trees

- Do not frequently use car

- Car pooling among colleagues

90.1

- Initiate to use renewable energy

- Have more nuclear power station

- Ban of CFCs from spray cans and styrofoam

- Recycle paper, tin and plastic

- Always prefer public transport

- Alternative energy like wind, waves and solar

- Choose to use hybrids cars

Idiosyncratic Statement:

- Reduce starvation among people

- Protect rare plants and animals

- Keep beaches clean

- Always prefer unleaded petrol

- Prefer healthy foods

- Apply sun-block cream

Several notable misconceptions were revealed among the students in the cures components. The majority of the group made an erroneous connection between climate change and protecting rare species. Habitat degradation from the effect of climate change might endanger certain species, but this action would not alleviate climate change. It shows that students are confused between cause and effect. Most of them also thought that keeping the beaches clean would will curb the effect of climate change. Groves and Pugh (1999) found that $72 \%$ of pre-service primary teachers believed that keeping the beach clean would help to reduce the greenhouse effect. This action is generally environmentally sympathetic but has 
nothing to do with the solution of the problem. The most prevalent misconception, however, was related to unleaded petrol and sunblock cream. Students were apparently confused between climate change, air pollution and lead compound. They believed that applying sun-block cream might effectively protect their skin from harmful sun rays, and that is true. However, believing that it could be the solution for climate change is definitely a misconception.

\section{Environmental Attitudes}

Table 5 summarizes the frequency distribution, mean score and standard deviation for each of the eleven items of the environmental concern scale. The mean score for negatively worded items (Q1, Q3, Q6, Q7 and Q11) were reversed so that high scores represented positive environmental attitudes.

Table 5

Frequency distribution, mean and standard deviation of environmental attitudes

\begin{tabular}{rrrrrrr} 
Item & SA $(\%)$ & $\mathrm{A}(\%)$ & $\mathrm{D}(\%)$ & $\mathrm{S} \mathrm{D}(\%)$ & Mean & $\mathrm{SD}$ \\
\hline $\mathrm{Q} 2$ & 1.2 & 1.7 & 23.7 & 73.4 & 3.69 & .564 \\
$\mathrm{Q} 7$ & 64.2 & 34.1 & .6 & 1.2 & 3.61 & .566 \\
$\mathrm{Q} 4$ & 1.2 & 5.2 & 35.8 & 57.8 & 3.50 & .653 \\
$\mathrm{Q} 1$ & 34.3 & 58.7 & 5.8 & 1.2 & 3.26 & .618 \\
$\mathrm{Q} 5$ & 1.7 & 9.3 & 53.5 & 35.5 & 3.23 & .685 \\
$\mathrm{Q} 11$ & 23.1 & 69.9 & 6.4 & 0.6 & 3.16 & .543 \\
$\mathrm{Q} 6$ & 30.6 & 56.6 & 10.4 & 2.3 & 3.16 & .694 \\
$\mathrm{Q} 3$ & 20.2 & 0 & 69.9 & 9.8 & 3.10 & .540 \\
$\mathrm{Q} 8$ & 4.6 & 15.0 & 62.4 & 17.9 & 2.94 & .717 \\
$\mathrm{Q} 9$ & 6.9 & 41.0 & 48.6 & 3.5 & 2.49 & .679 \\
$\mathrm{Q} 10$ & 8.1 & 52.6 & 35.8 & 3.5 & 2.35 & .679 \\
\hline
\end{tabular}

$\mathrm{SA}=$ strongly agree $; \mathrm{A}=$ agree $; \mathrm{D}=$ disagree $; \mathrm{SD}=$ strongly disagree

The results indicate that the respondents showed overwhelmingly positive environmental attitudes. The mean scores ranged from 2.35 to 3.69 based on a four-point scale. As future teachers, they strongly 
advocated the need for courses focusing on the conservation of natural resources to be taught in schools (Q7). The respondents also showed very strong attitudes on conservation of wild animals and natural resources (Q2 and Q7 respectively). Indeed, they strongly urged the government to tackle the pollution problems by introducing harsh measures. In contrast, two items (Q9: Anti-pollution organizations more interested in disrupting society than they are in fighting pollution; and Q10: Development of anti-pollution technology by local industries) obtained the lowest mean scores.

\section{Table 6}

Frequency Distribution, Mean and Standard Deviation of Environmental Behaviours

\begin{tabular}{ccccccc}
\hline Item & SA $(\%)$ & A $(\%)$ & D $(\%)$ & S D $(\%)$ & Mean & SD \\
\hline Q5 & 69.9 & 30.1 & 0 & 0 & 3.70 & .460 \\
Q1 & 59.5 & 38.7 & 1.7 & 0 & 3.58 & .529 \\
Q2 & 53.8 & 45.7 & .6 & 0 & 3.53 & .512 \\
Q4 & 53.2 & 44.5 & 2.3 & 0 & 3.51 & .546 \\
Q3 & 50.3 & 47.4 & 2.3 & 0 & 3.48 & .545 \\
Q7 & 46.8 & 52.6 & .6 & 0 & 3.46 & .512 \\
Q8 & 45.7 & 54.3 & 0 & 0 & 3.46 & .500 \\
Q9 & 39.0 & 58.7 & 1.7 & .6 & 3.36 & .550 \\
Q6 & 39.3 & 55.5 & 5.2 & 0 & 3.34 & .575 \\
Q10 & 31.8 & 55.5 & 11.0 & 1.7 & 3.17 & .685 \\
Q11 & 6.9 & 20.8 & 48.0 & 24.3 & 2.10 & .850 \\
\hline
\end{tabular}

$\mathrm{SA}=$ strongly agree $; \mathrm{A}=$ agree $; \mathrm{D}=$ disagree $; \mathrm{SD}=$ strongly disagree

\section{Environmental Behaviours}

Table 6 shows the frequency distribution, mean and standard deviation for the items on environmental behaviours. The mean score for each item was reversed so that a high score represented a positive environmental behaviour. The mean scores ranged from 2.10 to 3.70. The three items which received high mean scores were Q5 (support environmental education in schools), Q1 (willing to 
actively participate in paper recycling), and Q2 (planting more trees near house premises). The lowest mean score was exhibited for item Q11 which asked the respondents to support an increase on gasoline (petrol) prices. In addition, Q10 (to use public transportation more than they do now) also received a low mean score. For the lowest ranked items, the pattern suggested that students were reluctant to make any form of behaviour changes that might affect their life style and comfort such as paying more than what they have to currently (such as paying for the hike-up of fuel price and installing higher-priced energy saving bulbs) or using public transportation more frequently. Fortner et al., (2000) concluded from their studies that students are less likely to adopt the behaviours which could bring about direct, significant changes in their convenience and economic conditions. However, the results indicated that in general, students would still be willing to adopt environmentally responsible behaviours.

Table 7

Interrelation Between Environmental Knowledge, Attitudes and Behaviour

\begin{tabular}{lccc}
\hline Variable & Behaviour & Attitudes & Knowledge \\
\hline Behaviour & - & & \\
Attitudes & .063 & - & \\
Knowledge & .124 & -.081 & - \\
\hline
\end{tabular}

Note. All correlations are not significant

\section{The Environmental Knowledge-Attitude-Behaviour Relation}

Correlation analysis was performed to identify possible relationships among the three variables: knowledge, attitudes and behaviour. Pearson's product moment correlation $(r)$ was calculated to show the strength of the relationships among the variables investigated. Previous research found that a positive relationship existed between environmental knowledge and attitude toward environment. It was suggested that knowledge may act as a mediating variable between attitudes and behaviour (Arbuthnot \& Lingg, 1975). Several researchers argued that an increase in knowledge about 
the environment was necessary for improving attitudes towards the environment (Arcury, 1990). The hypothesis that greater environmental knowledge is positively correlated with environmental attitudes was not supported by the data from this study (Table 7). There is no statistically significant relationship between knowledge and attitude towards the environment, attitudes and behaviour and knowledge and behaviour.

\section{CONCLUSION}

The results from the present study can be summarized as follows: for the knowledge component, students' environmental knowledge is generally at the moderate level with several notable misconceptions like assuming aerosol spray and refrigerators, space programmes and holes in the ozone layers are factors that exacerbate climate change; and climate change will result in an increase in the prevalence of skin cancer. They believed that unleaded petrol and applying sunblock cream could be the solution for climate change. This presents a challenge to teacher-education institutions to spend more time teaching the science content of climate change to pre-service teachers and to employ pedagogy that is most conducive to student (preservice teacher) engagement (Lyons, 2005). The science of climate change can be an exciting vehicle for teaching and illustrating physical, chemical and biological concepts meaningfully. To bring life to this global climate change situation in the classroom, our teachers must have a solid understanding of the magnitude of the problem and be prepared to deliver engaging instruction concerning these concepts. Since education has the possibility of making real change in people's values, it is therefore important to make sure that high quality environmental education is a part of the educational system.

The findings also showed that students had positive environmental attitudes and were very willing to adopt proenvironmental behaviours such as actively participating in paper recycling, supporting environmental education in schools and planting more trees near house premises. However, they were less likely to adopt behaviours which could directly affect their convenience and economic conditions. The findings also showed no significant relationship between the three variables investigated i.e. knowledge, attitudes and behaviours. These results should inform the development of teacher-education programmes to ensure 
future teachers are prepared with the knowledge, attitudes and behaviours regarding environmental issues to engage and empower their students. The pre-service teachers need to be engaged in class discussions on environmental issues that are meaningful to them and related to their everyday lives. Students can be assigned to conduct an in-depth research on environmental issues and present the results in classroom open discussion. During the discussions, students will be exposed to a variety of ideas from other students and the exchange of ideas among them helps the students to evaluate as well as correct their pre-existing conceptions. Students also can be encouraged to do extensive research on environmental issues which can also help to correct their misconceptions in some rising issues, especially environmental problems. Further research, such as qualitative and longitudinal studies, is needed to investigate deeply the enhancement of students`attitudes and behaviours, as well as the formation of true environmental knowledge.

\section{REFERENCES}

Aini, M. S., Fakhrul-Razi, A., Laily, H. J., \& Jariah, M. (2003). Environmental concern, knowledge and practices gap among Malaysian teachers. International Journal of Sustainability in Higher Education, 4(4), 305-313.

- American Geophysical Union (AGU). (2007). Human Impacts on Climate (AGU Position Statement). Retrieved from http:// www.agu.org/sci_soc/policy/positions/ climate_change2008. shtm

Arba'at, H., Kamisah, O., \& Pudin, S. (2009). The adults non-formal environmental education (EE):A scenario in Sabah, Malaysia. Procedia Social and Behavioral Sciences, 1, 2306-2311.

Arbuthnot, J., \& Lingg, S. (1975). A comparison of French and American environmental behaviors, knowledge, and attitudes. International Journal of Psychology, 10(4 ) 275 - 281.

Arcury, T.A. (1990). Environmental attitude and environmental knowledge. Human Organization, 49, 300-304.

Boon, H. J. (2010). Climate change? Who knows? A comparison of secondary students and service teachers. Australian Journal of Teacher Education, 35(1), 104-120.

Bostrom, A., Morgan, M.G., Fischhoff, B., \& Read, D. (1994). What do people know about global climate change? Mental models. Risk Analysis, 14( 6), 959-970. 
Boyes, E., Chamber, W. \& Stanisstreet, M. (1993). The greenhouse effect: Children's perceptions of causes, consequences and cures. International Journal of Science Education, 15, 531552.

Boyes, E., Chambers, W., \& Stanistreet, M. (1995) Trainee primary teachers' ideas about the ozone layer. Environmental Education Research, 1(2), 133-145.

Chan, K. K.W. (1996). Environmental attitudes and behaviour of secondary school students in Hong Kong. The Environmentalist, 16, 297-306.

DeChano, L. M.(2006). A multi-country examination of the relationship between environmental knowledge and attitudes. International Research in Geographical and Environmental Education, 15(1), 15-28.

Fortner, R. W., Lee, J-Y., Corney, J. R., Romanello, S., Bonnell, J., Luthy, B. F., C., \& Ntsiko, N. (2000). Public understanding of climate change: Certainty and willingness to act. Environmental Education Research, 6(2), 127-141.

Grodzinska-Jurczak, M., Bartosiewicz, A., Twardowska, A., \& Ballantyne, R. (2003). Evaluating the impact of a school waste education programme upon students', teachers' and parents' environmental knowledge, attitudes and behaviour. International Research in Geographical and Environmental Education, 12 (2).

Groves, F., \& Pugh, A. (1999). Elementary pre-service teacher perceptions of the greenhouse effect. Journal of Science Eduational and Technology, 8,75-85.

Groves, F., \& Pugh, A. (2002). Cognitive illusions to learning as hindrances to complex environmental issues. Journal of Science Education and Technology, 11, 381-390.

Hooper, J.K. (1988). Teacher cognitions of wildlife management concepts. Journal of Environmental Education, 19, 15-19.

Huffington Post. (2009). Obama UN climate change speech. Retrieved from http://www.huffingtonpost.com.

IPCC. (2007). Climate change 2007: Synthesis report, summary for policy makers. Retrieved from http://www.ipcc.ch.

Kaplowitz, M. D., \& Levine R. (2005). How environmental knowledge measures up at a big ten university. Environmental Education Research, 11(2), 143-160.

Khalid, T. (2003). Pre-service high school teachers' perceptions of three environmental phenomena. Environmental Education Research, 9(1), 35-50. 
Kilinc, A., Stanisstreet, M., \& Boyes, E. (2008). Turkish students' ideas about global warming. International Journal of Environment and Science Education, 3(2), 89-98.

King, W. R., \& He, J. (2005). External validity in survey research. Communications of the Association for Information Systems, 16, 880-894.

Kyridis, A., Mavriki, E., \& Tsakridou, H. (2005). An analysis of attitudes of pedagogical students towards environmental education in Greece. International Journal of Sustainability in Higher Education, 6(1), 54-64.

Ministry of Science, Technology and the Environment (MOSTE). (2002). National policy on the environment. Bandar Baru Bangi, Selangor: Ministry of Science, Technology and the Environment.

Papadimitriou, V. (2004). Prospective primary teachers` understanding of climate change, greenhouse effects, and ozone layer depletion. Journal of Science Education and Technology, 13(2), 299-307.

Pekel, F. O., \& Ozay, E. (2005). Turkish high school students` perceptions of ozone layer depletion. Applied Environmental Education \& Communication, 4(2), 115-123.

Rye, J., Rubba, P., \& Wiesenmayer, R. (1997). An investigation of middle school students' alternative conceptions of global warming. International Journal of Science Education, 19(5), $527-551$.

Sharifah Norhaidah, S. I. (2006). Exploring environmental behaviours, attitudes and knowledge among university students: Positioning the concept of sustainable development within Malaysian education. Journal of Science and Mathematics Education in S.E Asia, 29(1), 79-97.

Sharifah, A., Laily, P., \& Nurizan, Y. (2005). Towards sustainable consumputions: An examination of environmental knowledge among Malaysians. International Journal of Consumer Studies, 29(5), 426-436.

Skanavis, C., Petreniti, V., \& Giannopoulou, K. (2004). Educators and environmental education in Greece. Protection and Restoration of the Environment VII: Social, Cultural, Educational and Sustainability Issues, 7(2).

Summers, M. (1994). Science in the primary school: The problem of teachers' curriculum expertise. The Curriculum Journal, 5, 179-193. 
Summers, M., Kruger, K., \& Childs, A. (2001). Understanding the science of environmental issues: Development of a subject knowledge guide for primary teacher education. International Journal of Science Education, 23, 33-53.

Summers, M., Kruger, C., Childs, A., \& Mant, G. (2000). Primary school teachers' understanding of environmental issues: An interview study. Environmental Education Research 6(4), 293-312.

Susan, P., Tagi, K., \& Periasamy, A. (2005). Environmental education in Malaysia and Japan: A comparative assessment. Paper presented at the International Conferences of Education for Sustainable Future, Ahmedabad, January, 18-20.

Nguyen, T.T. (2001). Awareness of Vietnamese primary school teachers on environmental education. International Research in Geographical and Environmental Education, 10(4),429444.

Thiagarajan, N., and Nor Shidawati, A.R. (2005). The implementation of EE in Malaysian Schools: A NGO's overview. Paper Presented at Best of Both Worlds International Conference on Environmental Education for Sustainable Development, Kuala Lumpur, Malaysia, September.

Tuncer, G. , Sungur, S., Tekkaya, C., \& Ertepinar, H. (2007). A comparative study on pre-Service teachers' and elementary students' attitudes towards the environment. International Research in Geographical and Environmental Education, 16(2), 188-198.

UNESCO-UNEP. (1978). The Tbilisi decleration: Final report intergovernmental conference on environmental education. Organized by UNESCO in cooperatuion with UNEP, Tbilisi, USSR, 14-26 October 1977, Paris, France: UNESCO ED/ $\mathrm{MD} / 49$.

Volk, T.L., \& McBeth, B. (1997) Environmental Literacy in the United States. Troy, OH: North American Association for Environmental Education.

Weigel, R., \& Weigel, J. (1978) Environmental concern: The development of a measure. Environment and Behaviour, 10, 3-5. 


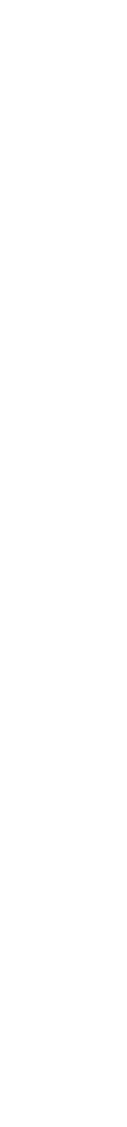

